\begin{tabular}{|c|c|c|}
\hline$\underset{P \cup B L I C A T I O N}{\operatorname{NF}}$ & $\begin{array}{l}\text { International Journal of Advanced Engineering, Management and Science } \\
\text { (IJAEMS) } \\
\text { Peer-Reviewed Journal } \\
\text { ISSN: } 2454-1311 \text { / Vol-7, Issue-9; Sep, } 2021 \\
\text { Journal Home Page: } \text { https://ijaems.com/ } \\
\text { Article DOI: https://dx.doi.org/10.22161/ijaems.79.3 }\end{array}$ & (1) \\
\hline
\end{tabular}

\title{
An Inquiry on the Self-Esteem and Self-Efficacy Level of Information Technology Students
}

\author{
Ruth G. Luciano, Cris Norman P. Olipas
}

College of Information and Communications Technology, Nueva Ecija University of Science and Technology, Philippines

Received: 06 Aug 2021; Received in revised form: 03 Sep 2021; Accepted: 10 Sep 2021; Available online: 20 Sep 2021

\begin{abstract}
This study aimed to identify, analyze and determine the level of self-efficacy and self-esteem of B.S. Information Technology (BSIT) students of a higher learning institution in Nueva Ecija, Philippines. It was conducted during the $1^{\text {st }}$ Semester of the academic year 2019-2020. This research utilized descriptive approach to describe the level of self-esteem and self-efficacy of the students and to draw valuable insights that may contribute to the improvement of the teaching and learning practices of the faculty members in the college. The researchers used random sampling to ensure that all year levels are well represented in the study. There were 285 students who voluntarily responded after the researchers explained to them the purpose of this study. Responses were tallied, summarized and interpreted. Results show that the level of self-esteem and self-efficacy of the students were moderate/medium $(W M=2.03$, WM=2.08). This indicates that depending on the given situation or context, students may increase or decrease the level of their self-esteem and self-efficacy. This study suggest that students may be exposed to more activities that may help them improve their self-esteem and selfefficacy to greatly contribute to their holistic development. Future studies may be conducted to a larger number of respondents and to understand the link between self-efficacy and self-esteem on their academic performance, drop-out rates, and retention rates.
\end{abstract}

Keywords_ Information Technology, Self-Efficacy, Self-Esteem

\section{INTRODUCTION}

The mastery of information, ingrained knowledge and understanding, and expanded use of technological advancements are the goals of education in the twenty-first century (Stone, 2014). It encompasses the holistic development of the learner in order to be fully equipped for the world of work, to contribute to economic development, and to uplift the quality of life. Schools have the responsibility to contribute to the attainment of these goals. There has been a perception that schools should stress intellectual growth over other factors, but according to Kohn (2015), education's primary goal should be to produce competent, caring, loving, and likeable individuals. Apart from equipping the learners' cognitive aspect, affective domain must also be considered. Thus, looking at the self-esteem and self-efficacy of the learners help in understanding how to greatly help them.
Several educational studies have shown the relevance of self-esteem and self-efficacy in the school system, notably on student performance. Self-esteem is defined as a psychological trait that involves self-judgment based on one's ideals about humans (Alesi et al, 2012). It entails being conscious of one's value system as well as one's emotional assessment of one's self-worth. (Schunk, 1985). People who have a high degree of self-esteem have a high level of social adjustment (Martin et al, 2014). Students must have good self-esteem to strengthen social skills and ability to cultivate supportive and lasting relationship (Watson, 2020).

On the other hand, self-efficacy is a person's conviction in his or her ability to carry out the actions required to achieve certain performance goal (Bandura, 1977). It is the belief in one's ability to succeed. Relevant to a specific task or area of knowledge or performance, self-efficacy 
shapes the behaviors and strategies that help pursue one's goal (Gunn, 2020).

Literature reviewed have shown the impact of self-esteem and self-efficacy to students. Wood (1987) conducted four studies to examine the relationship between self-efficacy and performance in college course. It was found out that self-efficacy is significantly related to academic performance and to self-set academic grade goals. Academic self-efficacy is an essential factor influencing academic performance among students (Hayaat et al, 2020). The higher the self-efficacy among the students, the better performance and results they can get compared to students with low self-efficacy (Ahmad \& Safaria, 2013).

On the other hand, Arshad et al (2015) found that there was a significant relationship between self-esteem and academic performance among university students. Moreover, significant difference was found out between male and female students. Meanwhile, Zao et al (2021) asserts that self-esteem positively predicted academic engagement among students.

Based from reviewed literature, self-esteem and selfefficacy affects students in different forms, both positive and negative. This study contributes to the existing body of knowledge by providing insights about the level of selfesteem and self-efficacy among Information Technology students. Further, this study aims to answer the following:

1. What is the demographic profile of the BSIT students based on:

\section{1. age; and}

1.2. sex?

2. What is the level of the self-esteem of the BSIT students?

3. What is their level of self-efficacy?

\section{METHODOLOGY}

A research design is a blueprint or strategy that is produced particularly to respond to the research topic (Dulock, 1993). Descriptive research aims to "describe" the variables under investigation without identifying its connection to other variables. The main goal is to provide information about the relevant features or details of the variables under study.

This study was conducted in a higher learning institution in Nueva Ecija, Philippines. It involved 285 IT studentrespondents based from the result of the random sampling conducted during the second semester of academic year 2019-2020.

Three-part survey instrument was used for this study. The first part covered the respondent's demographic profile such as age and sex. The second part was the self-esteem This article can be downloaded from here: www.ijaems.com checklist adapted from Lawrence (2006). It consisted of 48-item inventory divided into 10 sections namely; (1) unrealistic perception about self, (2) weak foundation for positive self-esteem, (3) not confident for school works, (4) does not cope well with failure, (5) finds it hard to accept responsibility for own actions, (6) negative perceptions from others, (7) easily lead, (8) image is very important, (9) does not have positive friendship and (10) eating pattern disturbed. The third part of the instrument solicits the self-efficacy level of the respondents. It is composed of 12-item statements where majority of the items were taken from the study conducted by McKenzie (1999).

To ensure that the instrument was valid and reliable, reliability analysis was done. As shown in Table 1, results indicate that the instrument was acceptable based from the Cronbach's Alpha value of .917 for Self-Esteem instrument and .886 for Self-Efficacy instrument.

Table 1: Reliability Analysis

\begin{tabular}{lcc}
\hline \multicolumn{1}{c}{ Items } & $\begin{array}{c}\text { Cronbach's } \\
\text { Alpha }\end{array}$ & No. Of Item \\
\hline Self-Esteem & .917 & 48 \\
Self-Efficacy & .886 & 12 \\
\hline
\end{tabular}

In interpreting the answers and the computed results, scoring guide and rating scale is necessary. Table 2 presents the scoring guide used for this study.

Table 2: Scoring Guide

\begin{tabular}{cll}
\hline Range & \multicolumn{1}{c}{$\begin{array}{c}\text { Verbal } \\
\text { Description }\end{array}$} & Interpretation \\
\hline $2.21-3.00$ & High & $\begin{array}{l}\text { Applies to some } \\
\text { extent }\end{array}$ \\
$1.71-2.20$ & Medium & Certainly applies \\
$1.00-1.70$ & Low & Strongly applies \\
\hline
\end{tabular}

To gather the needed data, the researchers' hand-over survey questionnaire to the randomly selected respondents. The researchers explained the contents of the instrument to the respondents and ensured them that the gathered data will be treated for research purpose only with utmost anonymity and confidentiality. After the researchers answered the queries related to answering the instrument, the respondents took time to answer the survey questionnaire.

After the researchers handed over the instrument to 285 respondents, they started data encoding, data cleaning, data 
organization, and data treatment. Data treatment and analysis was done using Statistical Package for Social Sciences (SPSS) version 20. Appropriate statistical tools and techniques were used to come up with relevant and reliable results.

\section{RESULTS AND DISCUSSION}

\section{A. Demographic Profile of the Respondents}

Figure 1 below presents the demographic profile of the respondents based on their age. Results revealed that among the 285 IT students, $13 \%$ were 15 to 17 years old, $64 \%$ were 18 to 20 years old, $19 \%$ were 21 to 23 years old,

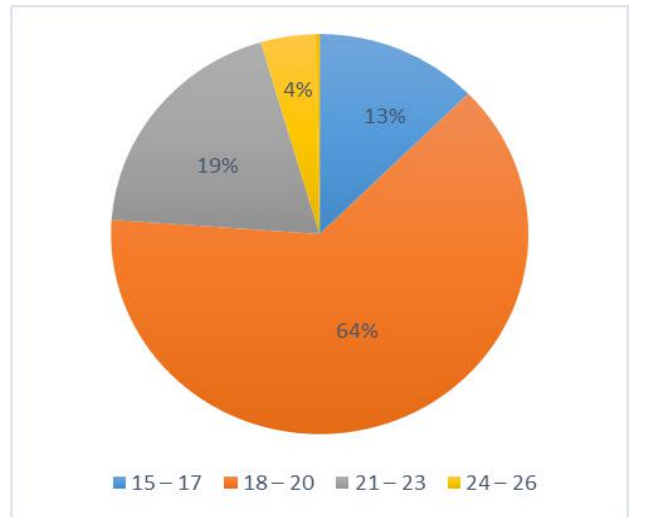

Fig. 1 -Demographic Profile based on Age

and $4 \%$ were 24 to 26 years old.

In figure $2,66 \%$ of the respondents were male and $34 \%$ were female. Results revealed a $32 \%$ gap based on sex. In different computing programs, several studies revealed a significant gap between male and female (Chan et al, 2000; Luciano, et al., 2020; Olipas and Cochanco, 2021). In a study conducted by Olipas and Luciano (2020), more male enrolled in IT program compared to female students posing an opportunity for the college to devise programs and activities to narrow the gender gap among students in

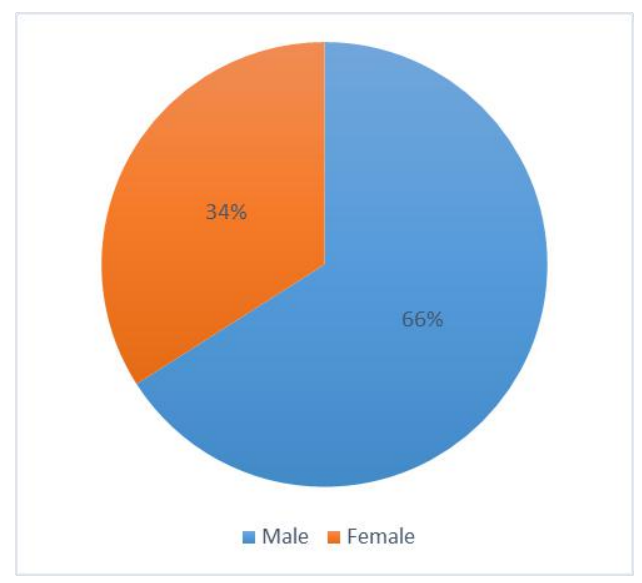

Fig. 2 -Demographic Profile based on Sex computing programs

\section{B. Level of Self-Esteem of the BSIT Students}

Table 3: Level of Self-Esteem of the BSIT Students

\begin{tabular}{|c|c|c|c|}
\hline Item & WM & VI & Rank \\
\hline $\begin{array}{l}\text { Unrealistic Perception } \\
\text { about self }\end{array}$ & 2.02 & $\begin{array}{l}\text { Certainly } \\
\text { Applies }\end{array}$ & 5 \\
\hline $\begin{array}{l}\text { Weak Foundation for } \\
\text { Positive Self-Esteem }\end{array}$ & 2.03 & $\begin{array}{l}\text { Certainly } \\
\text { Applies }\end{array}$ & 4 \\
\hline $\begin{array}{l}\text { Not Confident for School } \\
\text { Works }\end{array}$ & 2.06 & $\begin{array}{l}\text { Certainly } \\
\text { Applies }\end{array}$ & 2 \\
\hline $\begin{array}{l}\text { Does Not Cope well with } \\
\text { failure }\end{array}$ & 2.03 & $\begin{array}{l}\text { Certainly } \\
\text { Applies }\end{array}$ & 4 \\
\hline $\begin{array}{l}\text { Finds it hard to accept } \\
\text { responsibility for own } \\
\text { actions }\end{array}$ & 2.04 & $\begin{array}{l}\text { Certainly } \\
\text { Applies }\end{array}$ & 3 \\
\hline $\begin{array}{l}\text { Negative Perceptions from } \\
\text { others }\end{array}$ & 2.03 & $\begin{array}{l}\text { Certainly } \\
\text { Applies }\end{array}$ & 4 \\
\hline Easily Lead & 2.04 & $\begin{array}{l}\text { Certainly } \\
\text { Applies }\end{array}$ & 3 \\
\hline Image is very important & 2.01 & $\begin{array}{l}\text { Certainly } \\
\text { Applies }\end{array}$ & 6 \\
\hline $\begin{array}{l}\text { Does not have positive } \\
\text { friendship }\end{array}$ & 2.06 & $\begin{array}{l}\text { Certainly } \\
\text { Applies }\end{array}$ & 2 \\
\hline Eating Pattern Disturbed & 2.07 & $\begin{array}{l}\text { Certainly } \\
\text { Applies }\end{array}$ & 1 \\
\hline Overall Grand Mean & \multicolumn{2}{|c|}{2.04} & \\
\hline Self-Esteem Level & \multicolumn{2}{|c|}{ Medium } & \\
\hline
\end{tabular}

Table 3 presents the result of the evaluation on the level of self-esteem among the BSIT students. Respondents have reported that self-esteem have greatly affected their eating patterns $(\mathrm{WM}=2.07)$, their positive friendship to others (WM=2.06), and not confident for school works $(\mathrm{WM}=2.06)$. Further, students find it hard to accept responsibility for own actions (WM=2.04), easily lead $(\mathrm{WM}=2.04)$, has negative perception from others (WM=2.03), do not cope well with failure ( $\mathrm{WM}=2.03)$, and has weak foundation for positive self-esteem $(\mathrm{WM}=2.03)$. It may also certainly apply that for the student-respondents image is very important $(\mathrm{WM}=2.01)$, and their unrealistic perception about self (WM=2.02).

Medium to Low Self-Esteem among students have significant impact to their academic performance, to their relationship to others, and their view of oneself. Results revealed that IT students have a medium level of self- 
esteem as reflected in the overall grand mean of 2.04. This shows that in certain situations, their self-esteem may change due to their exposure to several factors other than those mentioned above.

\section{Level of Self-Efficacy of the BSIT Students}

Table 4: Level of Self-Efficacy of BSIT Students

\begin{tabular}{|c|c|c|}
\hline Item & WM & VI \\
\hline Self-Efficacy & 2.08 & $\begin{array}{c}\text { Certainly } \\
\text { Applies }\end{array}$ \\
\hline
\end{tabular}

As shown in Table 4, the self-efficacy of the BSIT students can also be considered medium as reflected in the mean score of 2.08. Self-efficacy significantly affects their academic performance in many ways; thus, it is necessary to help them improve their self-efficacy so they can also improve the other aspects of their being.

\section{CONCLUSION AND RECOMMENDATIONS}

This study inquired about the level of self-esteem and selfefficacy of the BSIT students in a higher learning institution in Nueva Ecija, Philippines. It was participated by 285 randomly selected respondents. Based on the results, majority of the respondents, $64 \%$, were between ages 18-20 years old. There was a $32 \%$ gap between male and female respondents. The results of the assessment on self-esteem revealed that BSIT students have medium level of self-esteem as reflected in the over-all mean rating of 2.04. Also, the level of self-efficacy fell on the medium level as shown in the over-all mean rating of 2.08 .

Medium level of self-esteem and self-efficacy may affect the academic performance of the BSIT students. Thus, the following recommendations are presented.

1. The Gender and Development Unit of the College may utilize the data depicting gaps between Male and Female to come-up with activities or programs to contribute in narrowing gender gap in the computing program;

2. The CICT Guidance and Counselling Coordinators may consider the results in coming-up with activities that would help students improve the level of their self-esteem and self-efficacy; and

3. Future researches may be conducted to look at the factors affecting the level of self-esteem and selfefficacy among the BSIT students.

\section{REFERENCES}

[1] Stone, S. (2014). The Goal of Education in the $21^{\text {st }}$ Century. Teacherswithapps. Retrieved from

This article can be downloaded from here: $w w w . i j a e m s . c o m$ https://www.teacherswithapps.com/the-goal-of-educationin-the-21st-century/

[2] Kohn, Alfie (2015). What Does It Mean to Be Well-Educated? Retrieved from https://www.alfiekohn. org/article/meanwell-educated-article/.

[3] Alesi, M., Rappo, G., and Pepi, A. (2012). Self-esteem at school and self-handicapping in childhood: comparison of groups with learning disabilities. Psychol. Rep. 111, 952962. doi: 10.2466/15.10.PR0.111.6.952-962

[4] Schunk, D. H. (1985). Self-efficacy and classroom learning. Psychol. Sch. 22, 208-223. doi: 10.1002/15206807(198504)22:2<208::aid-pits2310220215>3.0.co;2-7

[5] Martin, F., Russell, S., and Seeley, J. (2014). Higher quality of life and lower depression for people on ART in Uganda as compared to a community control group. PLoS One 9:e105154. doi: 10.1371/journal.pone.0105154

[6] Watson, S. (2020). Improving self-esteem: how to help your students build confidence. Retrieved from https://www.thoughtco.com/improving-self-esteem-3110707

[7] Bandura, A. (1977). Self-efficacy: Toward a unifying theory of behavioral change. Psychological Review, 84(2), 191215.

[8] Gunn, J. (2020). How to Encourage Student Self-Efficacy. Retrieved from https://blog.shareto learn.com/leaderslink/build-student-self-efficacy/.

[9] Wood, R. E., \& Locke, E. A. (1987). The Relation of SelfEfficacy and Grade Goals to Academic Performance. Educational and Psychological Measurement, 47(4), 10131024. doi: $10.1177 / 0013164487474017$

[10] Hayat, A.A., Shateri, K., Amini, M. et al. (2020). Relationships between academic self-efficacy, learningrelated emotions, and metacognitive learning strategies with academic performance in medical students: a structural equation model. BMC Med Educ 20, 76. https://doi.org/10.1186/s12909-020-01995-9

[11] Ahmad, A. \& Safaria, T. (2013). Effects of Self-Efficacy on Students' Academic Performance. Journal of Education, Health, and Community Psychology. Vol. 2. No. 1.

[12] Arshad, M., Zaidi, S., Mahmood, K. (2015). Self-Esteem \& Academic Performance among University Students. Journal of Education and Practice. ISSN 2222-1735 (Paper) ISSN 2222-288X (Online). Vol.6, No.1.

[13] Ying, Z., Zeqing, Z., Chenchen, P., Lulu, Z. (2021). SelfEsteem and Academic Engagement Among Adolescents: A Moderated Mediation Model. Frontiers in Psychology. 12. ISSN=1664-1078. 10.3389/fpsyg.2021.690828

[14] Dulock, H. L. (1993). Research Design: Descriptive Research. Journal of Pediatric Oncology Nursing, 10(4), 154-157. https://doi.org/10.1177/104345429301000406

[15] McKenzie, Jill K. (1999). Correlation between Self-Efficacy and Self-Esteem in Students. University of Wisconsin-Stout https://minds.wisconsin.edu/ bitstream/handle/1793/39287/1999mckenzie.pdf?sequence= 1

[16] Lawrence, D. (2006). Enhancing Self-Esteem in the Classroom $3^{\text {rd }}$ Edition. SAGE Publication. ISBN 10-1-41292110-4 
[17] Chan, V., Stafford, K., Klawe, M., and Chen, G. (2000). Gender Differences in Vancouver Secondary Students' Interest Related to Information Technology Careers. Department of Computer Science. University of British Columbia

[18] Luciano, RG., et al (2020). Assessment of the Personal Skills of BSIT Students: A Basis for Training Plan Development. International Journal of Science Technology Research 2020; 9(3):6550-6555.

[19] Olipas, CNP., and Cochanco, RAG. (2021). The Information Technology Students' Cognitive Determinants and Its Relationship to Academic Performance. International Journal of Advanced Engineering Research and Science (IJAERS). ISSN 2349-6495(P) 2456-1908(O). Vol. 8 Issue 3. March 2021. https://dx.doi.org/10.22161/ijaers.83.39

[20] Olipas, CNP., and Luciano, RG. (2020). Understanding the Impact of Countdown Timer On the Academic Motivation and Computer Programming Anxiety of IT Students: The Case of A State University in the Philippines. International Journal of Scientific and Technology Research. Vol. 9 Issue 3 March 2020. ISSN 2277-8616 